\title{
Potentials of Cowpea (Vigna unguiculata l.) Seed Priming on Growth and Development on Arsenic Contaminated Soil
}

\author{
A. H .Erhenhi ${ }^{1 *}$, E. E. Lemy ${ }^{2}$, D. E. Vwioko ${ }^{3}$ and E. P. Monwuba ${ }^{1}$ \\ 'Department of Botany, Delta State University, Abraka, Nigeria; \\ erhenhiah@gmail.com, preciousaustine64@gmail.com \\ ${ }^{2}$ Department of Animal and Environmental Biology, University of Benin, Benin City, Nigeria; \\ emmalems03@gmail.com \\ ${ }^{3}$ Department of Plant Biology and Biotechnology, University of Benin, Benin City, Nigeria; \\ vwioko@yahoo.com
}

\begin{abstract}
Objectives: This study was carried out with the objectives of determining the growth potential of primed cowpea (Vigna unguiculata $L$.) seeds under different concentration of arsenic treated soil, specifically to ascertain the effects of salicylic treatment on growth properties of cowpea seeds treated with varying concentrations of arsenic acid. Methods/Statistical Analysis: Locally purchased seeds of cowpea treated with salicylic acid were grown on soil treated for 24 hrs by soaking with different concentrations $(0.0,50,100$ and $150 \mathrm{ppm})$ of arsenic acid before planting. $200 \mathrm{ml}$ of the arsenic acid treatments were also applied immediately after planting and every fourth day for the next weeks of the study to the contaminated soil while control received distilled water. Germination percentage was recorded based on protruded radical and plumule and growth parameter such as plant height was measure using meter rule from base to the apical bud of the plant. The parameters were observed for three weeks. Mean and standard deviations were calculated for the values recorded in the study. Findings: Arsenic acid had negative effects on the rate of germination of both the treated and untreated seeds. The highest germination rates (50\% and $75 \%)$ were recorded in the control of both the treated and untreated seeds. $20 \%$ and $25 \%$ germination was recorded for $50 \mathrm{ppm}$ treated and untreated soil while $100 \mathrm{ppm}$ and $150 \mathrm{ppm}$ did not show sign of germination. Plant height was affected by the pollutant with control having highest height in both treated seeds as well as in the control. This was followed by $50 \mathrm{ppm}$ concentration treatment with $100 \mathrm{ppm}$ and $150 \mathrm{ppm}$ showing no growth of plant. The research revealed that cowpea seeds were highly susceptible to the phytotoxic effects of arsenic acid and seed treatment with salicylic acid has no effect on germination and growth of cowpea seeds in contaminated soil. Applications/Improvements: This study therefore shows that the plant cannot serve as bioremediator in polluted environment. Therefore, appropriate measures should be taken to avoid arsenic contamination of cowpea farmlands.
\end{abstract}

Keywords: Arsenic Contaminant, Plant Growth, Seed Priming, Vigna unguiculata L

\section{Introduction}

The discharge or introduction of toxic materials into the environment is a problem globally ${ }^{1}$. Arsenic (As) element is believed to have fatal carcinogenic and toxic impact on plants, animals as well as humans ${ }^{2}$. Arsenic is intro-

${ }^{*}$ Author for correspondence 
duced into the environment through various processes either through natural weathering of arsenic associated minerals in the zone and through volcanic activity or by human anthropogenic activities such as use of fuel wood, exploratory/mining, smelting, fertilizers of arsenic based materials, pesticides for agriculture purposes and arsenic contaminated groundwater for irrigation ${ }^{3}$. The use of arsenicals in agriculture has led to the release of arsenic into the environment, hence resulting in oxidation and reduction changes in soil as well as negative impacts on plants yield and biomass generation ${ }^{4}$. Concentrations of arsenic in plants are low generally ${ }^{5}$. Arsenic speciation in soil is determined by different reactions and its uptake by plant in soil-plant system ${ }^{6}$. Although arsenic is non-essential for other organisms and plants, its uptake by different plant species depend to a great extent on the concentration, content and presence in the soil.

Being sessile in nature and increased anthropogenic activities in the advanced era, plants are exposed to innumerable abiotic stresses, such as heat, cold stress, salinity, heavy metals, ultraviolet radiation and nutrient changes ${ }^{\underline{ }}$. Under natural conditions, salinity has a multiple effect on plant growth by reducing water absorption, creating ion imbalance or turbulence that leads to plant toxicity. This negatively affects growth parameter viz. germination efficiency, leaf area, length and roots and shoot dry weight, protein synthesis, photosynthesis and chlorophyll, lipid breakdown and reactive oxygen species formation ${ }^{8}$. The presence of arsenic in soil affects plant yield, stunted growth and disrupt ions of normal physiological and metabolic functions ${ }^{1}$. Earlier studies revealed that arsenic in small amount boost or foster growth in plants but at high concentration, have provoked fatal or lethal response ${ }^{9}$ reported that Helianthus annuus L. had optimal functioning at low arsenic concentration but hindered both metabolic and biochemical functions which proved fatal to the plant.

The study of ${ }^{10}$ on the uptake of arsenic and phosphorus and the soil arsenic bioavailability at different growth stages of wheat and rape showed that winter wheat was much more sensitive to arsenic stress than rape. Wheat yields were elevated at low rates of arsenic addition $(<60$ $\mathrm{mg} / \mathrm{kg}$ ) but reduced at high rates of arsenic concentrations $(80-100 \mathrm{mg} / \mathrm{kg})$; while the growth of rape hadn't showed significant responses to arsenic addition. Arsenic concentrations in wheat and rape grains did not exceed the maximum permissible limit for food stuffs of $1.0 \mathrm{mg} /$ $\mathrm{kg}$. When soil arsenic concentration was less than $60 \mathrm{mg} /$ $\mathrm{kg}$, both wheat and rape could grow satisfactorily without adverse effects; when soil arsenic concentration was $80-100 \mathrm{mg} / \mathrm{kg}$, rape was more suitable to be planted than wheat.

Salicylic acid is a phenolic growth regulator that assumes conspicuous and expanded role in biochemical and physiological reaction to abiotic stress ${ }^{\underline{11}}$. It has been also revealed that exogenously applications of salicylic acid can significantly enhanced overall growth of plant under both salinity and non-salinity by adjusting antioxidants scavenging system. Furthermore, salicylic acid also reduced the destructive effects of several abiotic stresses by regulating proline concentration and other osmolytes production 2 . However, confirmation regarding the lessening of salinity stress by exogenous salicylic acid is slightly questioned as Arfan et al. ${ }^{12}$ recounted that spraying salicylic acid could balance direct salt stress activated development restraint, while no change happened at high convergences of salt stress. Therefore, the action of salicylic acid to suppress salt stress on concentration and plant species need to be further clarified. Additionally, the defensive role of phytohormones especially role of salicylic acid in ameliorating the detrimental effect of arsenic stress on plantsto increase its salt tolerance is mystical. The aim of this study is to determine the growth potential of primed cowpea (Vigna unguiculata L.) seeds under different concentration of arsenic treated soil.

\section{Materials And Methods}

\subsection{Description of Study Area}

The work was carried out in the Botanical Garden, Department of Botany, Faculty of Science, Delta State 
University, Abraka, Delta State, Nigeria. The area is a typical coastal plain terrain, monotonously lowland and flat with a gentle slope towards the Ethiope River. The climate is equatorial, hot $\left(23\right.$ to $\left.37^{\circ} \mathrm{C}\right)$ and high (50 to $70 \%)$. The dry season usually range from November to February while the raining season starts or commences in March through July to October where the maximum is obtained. Vegetation is rainforest, most of which has been decimated and replaced with farmlands and secondary forest $\frac{13}{3}$.

\subsection{Collection and Preparation of Materials}

Cowpea seeds were purchased from local market and soil sample (0-15 cm depth) collected from farm site in the study area. Arsenic trioxide $\mathrm{AS}_{2} \mathrm{O}_{3}$ salt used were purchased from local distributors. Different concentrations (ppm) of contamination were prepared $(50,100,150)$ by weighing their equivalent using digital balance in a measuring cylinder containing deionized water and stirred thoroughly.

\subsection{Seed Priming, Soil Treatment and Planting}

50 milligrams of salicylic acid was dissolved in one litre of deionized water to obtain $50 \mathrm{ppm}$ salicylic acid treatment.

The solution was poured in a beaker and viable cowpea seeds were soaked in the solution for two hours before planting. A total of 32 polypots containing $3.0 \mathrm{~g}$ of soil perforated at the bottom to allow flow of water prepared for the experiment. Four replications was setup for each treatment and the control (using deionized water only). Different concentrations of arsenic contaminant (50 ppm, $100 \mathrm{ppm}$ and $150 \mathrm{ppm}$ ) were applied to the soils and allowed to soak for 24 hours before planting. Four seeds of cowpea were sown on both contaminated and uncontaminated soils. $200 \mathrm{ml}$ of the treatments were also applied immediately after planting and every fourth day for the next weeks of the study to the contaminated soil.

\subsection{Germination and Growth Measurement}

Germination was recorded as radicle or plumule protruded for 14 days and the percentage germination was determined using the formula:

$$
\begin{aligned}
\text { Percentage germination }= & (\text { Number of seeds that ger- } \\
& \text { minated } / \text { Total seeds sown }) \\
& \text { x } 100
\end{aligned}
$$

Standard metre rule was used to measure the plant height from the soil level to the apical bud. This was carried out every week

\subsection{Statistical Analysis}

Mean and standard deviations were calculated for the values recorded in the study. Both the mean and standard deviations where performed where appropriate using the statistical package Microsoft - Excel Version-2010. One way analysis of variance was carried out to ascertain the response of the plants to the treatments.

\section{Results}

Effects of salicylic acid treated and untreated seeds of cowpea grown on different concentrations (ppm) of arsenic acid was evaluated in the present study, the results obtained from the determination of the effects of varying concentrations of arsenic acid on germination percentage of both treated and untreated cowpea seeds are presented in Tables 1 and 2. The results obtained showed that arsenic acid had negative effects on the rate of germination of both the treated and untreated seeds. The highest germination rates (50\% and $75 \%$ ) were recorded in the control of both the treated and untreated seeds. $20 \%$ and $25 \%$ germination was recorded for $50 \mathrm{ppm}$ treated and untreated soil while $100 \mathrm{ppm}$ and $150 \mathrm{ppm}$ did not show sign of germination.

Plant height which is a part of plant growth parameters required for the determination of the effects of pollution showed that the pollutant affected the growth of cowpea plant. Figures 1 and 2 shows the effects of the var- 
Table 1. Percentage germination (\%) of salicylic treated cowpea seeds grown on different concentrations of arsenic acid

\begin{tabular}{|c|c|c|c|c|c|}
\hline \multirow{2}{*}{ Conc. (ppm) } & \multicolumn{5}{|c|}{ Days After Planting } \\
\cline { 2 - 6 } & 3 DAP & 6 DAP & 9 DAP & 12 DAP & 14 DAP \\
\hline $0.0 \mathrm{ppm}$ & $15.0 \pm 1.14$ & $50.0 \pm 0.02$ & $50.0 \pm 0.02$ & $50.0 \pm 0.02$ & $50.0 \pm 0.02$ \\
\hline $50 \mathrm{ppm}$ & $10.0 \pm 0.15 .33$ & $20.0 \pm 2.10$ & $20.0 \pm 2.10$ & $20.0 \pm 2.10$ & $20.0 \pm 2.10$ \\
\hline $100 \mathrm{ppm}$ & $00 \pm 00$ & $00 \pm 00$ & $00 \pm 00$ & $00 \pm 00$ & $00 \pm 00$ \\
\hline $150 \mathrm{ppm}$ & $00 \pm 00$ & $00 \pm 00$ & $00 \pm 00$ & $00 \pm 00$ & $00 \pm 00$ \\
\hline
\end{tabular}

Results presented in Mean \pm SD

Table 2. Percentage germination of untreated cowpea seeds grown on different concentrations of arsenic acid

\begin{tabular}{|c|c|c|c|c|c|}
\hline \multirow{2}{*}{ Conc. (ppm) } & \multicolumn{5}{|c|}{ Days After Planting } \\
\cline { 2 - 6 } & 3 DAP & 6 DAP & 9 DAP & 12 DAP & 14 DAP \\
\hline $0.0 \mathrm{ppm}$ & $25.0 \pm 0.11$ & $50 \pm 12.01$ & $75.0 \pm 1.01$ & $75.0 \pm 1.01$ & $75.0 \pm 1.01$ \\
\hline $50 \mathrm{ppm}$ & $25.0 \pm 0.11$ & $25.0 \pm 0.11$ & $25.0 \pm 0.11$ & $25.0 \pm 0.11$ & $25.0 \pm 0.11$ \\
\hline $100 \mathrm{ppm}$ & $00 \pm 0.0$ & $00 \pm 0.0$ & $00 \pm 0.0$ & $00 \pm 0.0$ & $00 \pm 0.0$ \\
\hline $150 \mathrm{ppm}$ & $00 \pm 0.0$ & $00 \pm 0.0$ & $00 \pm 0.0$ & $00 \pm 0.0$ & $00 \pm 0.0$ \\
\hline
\end{tabular}

Results presented in Mean \pm SD

ious concentrations of arsenic contaminated soil on the height $(\mathrm{cm})$ of salicylic acid treated and untreated cowpea plant. The control recorded highest height in both treated seeds as well as in the control. This was followed by 50 ppm concentration treatment with $100 \mathrm{ppm}$ and $150 \mathrm{ppm}$ showing no growth of plant. 


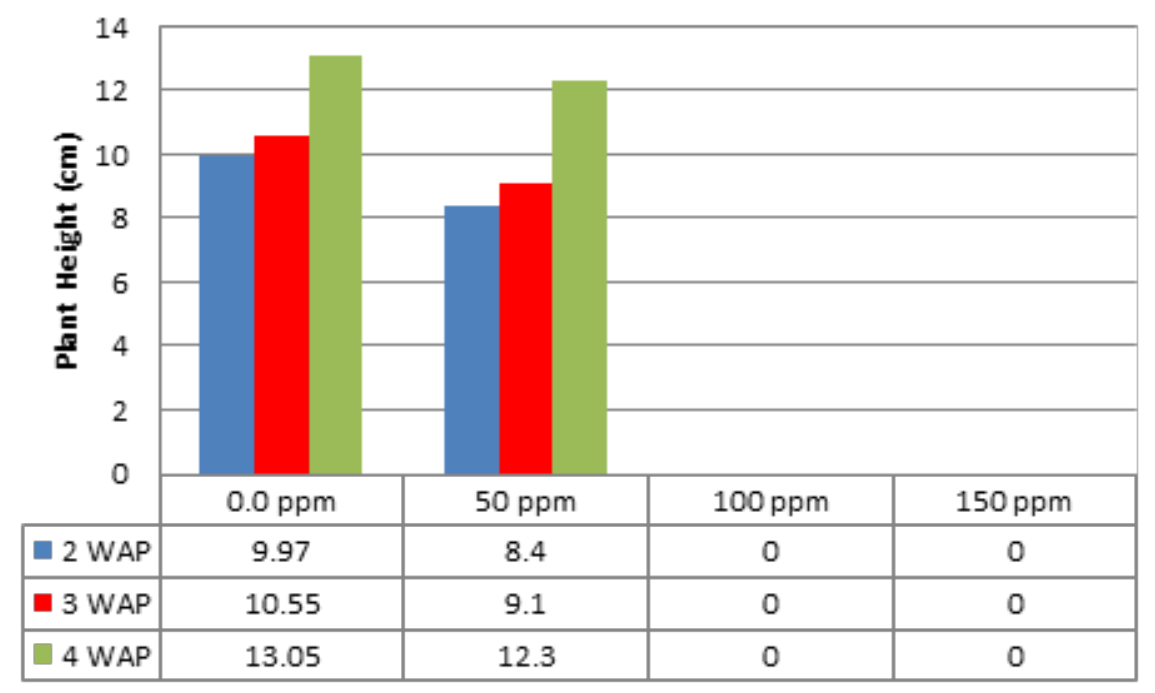

Figure 1. Plant height of salicylic treated cowpea sown in arsenic treated soil.

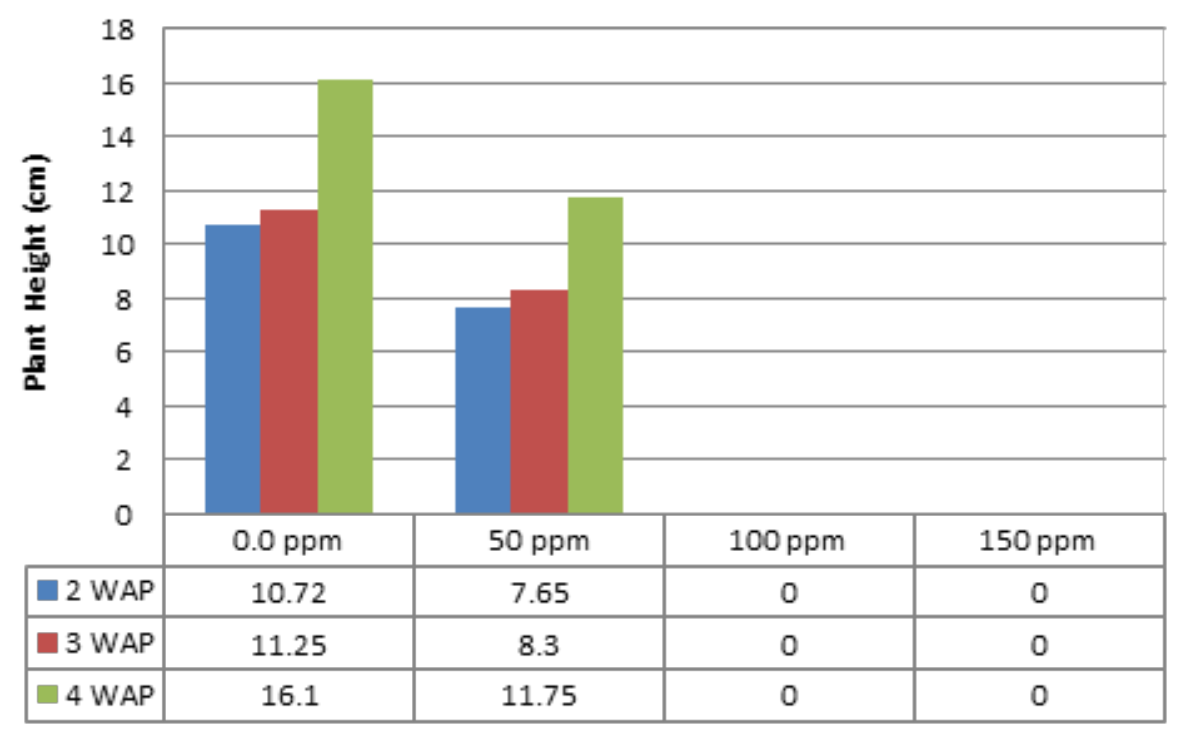

Figure 2. Height of unprimed cowpea seed sown in treated soil.

\section{Discussion}

The study compared the growth responses of primed and unprimed cowpea seeds sown in arsenic contaminated soil. It was noticed in the results that treated seeds showed no negative signs of growth and germination on seeds sown on arsenic contaminated soil as evidenced in the percentage germination and plant height. This result negates the suggestion that salicylic acid decreased the injury of salt stress to the plants, thereby increasing the germination rate as reported by $\underline{14}$ and $\mathrm{d}^{15}$. Application of arsenic acid resulted to decrease in the germination percentage. However, salicylic acid treatment did not improve the germination percentage. This study is in 
consonance with the report of $\frac{16}{16}$ who observed seeds treatment with salycilic acid and gibberellic acid and reported that gibberllic acid decreased germination percentage and germination rate to about 38 and $41 \%$ in $1 \mathrm{mMol}$ than control, respectively.

The study showed that plant uptake arsenic acid with high affinity thereby unable to germinate and grow accordingly. The affinity to absorb arsenic in plants could be low or high, hence it determines whether the normal performance of the plant could be disturbed or enhanced ${ }^{17}$. Poor germination and growth performance of plants sown in arsenic treated soil could have resulted from the toxic attributes associated with arsenic acid which when present in soil disturb plant normal functioning, alteration of plant metabolism, stunted growth of plant and low crop yield ${ }^{1}$.

At higher concentrations, cowpea could not germinate which shows that the plant could not tolerate certain level of arsenic. Also, at low concentration, there was observed germination and growth, although arsenic acid affected plant height and germination percentage. This is evidence in the report of $\frac{18}{}$. The report of ${ }^{19}$ stated the obvious effects of arsenic on the decreased growth of shoots and roots of Cicer arietinum L. and Oryza sativa L. The inability of plants to germinate, grow and survive could be attributed to the fact that the metabolic pathways as well as photosynthetic apparatus of the plants are disrupted ${ }^{20}$ as arsenic affects food production in plant, water uptake level, metabolic and biochemical processes.

The presence of arsenic in tissues of plants gives rise to peroxidase production at the early stage of plant growth before the visible changes of arsenic on the plant ${ }^{21}$.

\section{Conclusion}

This research showed the poisonous effects of arsenic acid on cowpea seeds. The work revealed that seed treatment with salicylic acid has no effect on germination and growth of cowpea seeds in contaminated soil. This therefore shows that the plant cannot serve as bioremediator in polluted environment.

\section{References}

1. Abbas G, Behzad M, Irshad B, Muhammad S, Nabeel KN, Muhammad IK, Muhammad A, Munawar HN. Arsenic uptake, toxicity, detoxification and speciation in plants: Physiological, biochemical and molecular aspects. International Journal of Environmental Research and Public Health. 2018; 15(1):59. https://doi.org/10.3390/ ijerph15010059.

2. Arsenic-induced metabolic disturbances and their mitigation mechanisms in crop plants: A review. 2016. https:// www.degruyter.com/view/j/biolog.2016.71.issue-4/ biolog-2016-0052/biolog-2016-0052.xml https://doi. org/10.1515/biolog-2016-0052.

3. Xiong T, Dumat C, Pierart A, Shahid M, Kang Y, Li N, Bertoni G, Laplanche C. Measurement of metal bioaccessibility in vegetables to improve human exposure assessments: Field study of soil-plant-atmosphere transfers in urban areas, South China. Environmental Geochemistry and Health. 2016; 38(6):1283-301. https://doi.org/10.1007/s10653-0169796-2.

4. Indira C. Effects of arsenic concentrations and forms on growth and arsenic uptake and accumulation by Indian mustard (Brassica juncea L.) genotypes. Journal of Central European Agriculture. 2016; 7(1):31-40..

5. Matschullat J. Arsenic in the geosphere - A review. Science of the Total Environment. 2000; 249(1-3):297-312. https:// doi.org/10.1016/S0048-9697(99)00524-0.

6. Rafiq M, Shahid M, Abbas G, Shamshad S, Khalid S, Niazi NK, Dumat C. Comparative effect of calcium and EDTA on arsenic uptake and physiological attributes of Pisum sativum. International Journal of Phytoremediation. 2017; 19(7):662-9. https://doi.org/10.1080/15226514.2016.12784 26.

7. Khan MIR, Khan NA. Salicylic acid and jasmonates: Approaches in abiotic stress tolerance. Journal of Plant Biochemistry and Physiology. 2013; 1(4):1-6. https://doi. org/10.4172/2329-9029.1000e113.

8. Parida AK, Das AB. Salt tolerance and salinity effects on plants: A review. Ecotoxicology and Environmental Safety. 2005; 60(3):324-49. https://doi.org/10.1016/j. ecoenv.2004.06.010

9. Imran MA, Muhammad NC, Rass MK, Zulfiqar A, Tariq M. Toxicity of arsenic (As) on seed germination of sunflower (Helianthus annuusL.). International Journal of Physical Sciences. 2013; 8(17):840-7. https://doi.org/10.5897/ IJPS2013.3894.

10. Liu X, Zhang S, Shan X, Zhu Y.G. Toxicity of arsenate and arsenite on germination seedling growth and amylolytic 
activity of wheat. Chemosphere. 2010; 61(2):293-301. https://doi.org/10.1016/j.chemosphere.2005.01.088.

11. Hayat Q, Hayat S, Irfan M, Ahmad A. Effect of exogenous salicylic acid under changing environment: A review. Environmental and Experimental Botany. 2010; 68(1):1425. https://doi.org/10.1016/j.envexpbot.2009.08.005.

12. Arfan M, Athar HR, Ashraf M. Does exogenous application of salicylic acid through the rooting medium modulate growth and photosynthetic capacity in two differently adapted spring wheat cultivars under salt stress? Journal of Plant Physiology. 2007; 164(6):685-94. https://doi. org/10.1016/j.jplph.2006.05.010.

13. Efe SI, Aruegodore PC. Aspect of microclimates in the Nigeria rural environment: The Abraka experience. Nigerian Journal of Research Product. 2003; 2(3):48-57..

14. Lee S, Kim SG, Park CM. Salicylic acid promotes seed germination under high salinity by modulating antioxidant activity in Arabidopsis. New Phytology. 2010; 188(2):62637. https://doi.org/10.1111/j.1469-8137.2010.03378.x.

15. Torabian AR. Effect of salicylic acid on germination and growth of alfalfa (Medicago sativa L.) seedlings under water potential loss at salinity stress. Plant Ecophysiology. 2010; 2(4):151-5..

16. Bahrani A, Pourreza J. Gibberlic acid and salicylic acid effects on seed germination and seedlings growth of wheat
(Triticum aestivumL.) under salt stress condition.World Applied Sciences Journal. 2012; 18(5):633-41..

17. Kumar S, Dubey RS, Tripathi RD, Chakrabarty D, Trivedi PK. Omics and biotechnology of arsenic stress and detoxification in plants: Current updates and prospective. Environment International. 2015; 74:221-30. https://doi. org/10.1016/j.envint.2014.10.019.

18. Arsenic removal from contaminated waters by Fe-based (hydr) oxides and its phytoavailability in soil-plant system. 2015. http://www.fedoa.unina.it/10120/.

19. Vromman D, Lutts S, Lefèvre I, Somer L, De Vreese O, Slejkovec Z, Quinet M. Effects of simultaneous arsenic and iron toxicities on rice (Oryza sativa L.) development, yieldrelated parameters and $\mathrm{As}$ and $\mathrm{Fe}$ accumulation in relation to As speciation in the grains. Plant Soil. 2013; 371(12):199-217. https://doi.org/10.1007/s11104-013-1676-2.

20. Abbas G, Saqib M, Akhtar J, Murtaza G, Shahid M, Hussain A. Relationship between rhizosphere acidification and phytoremediation in two acacia species. Journal of Soils and Sediments. 2017; 16(4):1392-9. https://doi.org/10.1007/ s11368-014-1051-9.

21. Stoeva N, Bineva T. Oxidative changes and photosynthesis in oat plants grown in as-contaminated soil. Bulgarian Journal of Plant Physiology. 2003; 29:87-95. 